\title{
Factores intra y extra escolares asociados al rezago educativo en comunidades vulnerables
}

\section{Intra and extra school factors associated with educational backwardness in vulnerable communities}

Investigación

\author{
Elizabeth Mendoza Cárdenas \\ Universidad Autónoma de Nuevo León-México \\ bettymendozac@yahoo.es \\ María Zúñiga Coronado \\ Universidad Autónoma de Nuevo León-México \\ maria.zunigacn@uanl.edu.mx
}

Recibido: 16 de agosto de 2015 / Aceptado: 10 de enero de 2017

\section{Resumen}

Ante la situación que presentan los niños y niñas del mundo, sobre todo los de los países en desarrollo, se establecen, con la participación de 189 países miembros de las Naciones Unidas, en el 2000, seis Objetivos de Desarrollo del Milenio dirigidos a la infancia. Uno de ellos pretende asegurar para el 2015 que todos los niños y niñas terminen la enseñanza primaria. Una serie de factores individuales y estructurales impiden el acceso o permanencia de los niños y niñas en la escuela, sin embargo, de acuerdo a una serie de estudios realizados, los factores externos, como la pobreza, y el género resultan ser los factores clave que mantiene a los niñ@s alejad@s de la escuela. El presente trabajo tiene por objetivo mostrar los resultados de un estudio exploratorio realizado desde el enfoque mixto sobre la percepción que tienen directivos, profesores y habitantes de nueve agebs del Polígono San Bernabé, del municipio de Monterrey, sobre los factores que promueven el rezago educativo de los estudiantes que cursan la enseñanza básica. Se dará a conocer, además, las principales estrategias utilizadas en las instituciones educativas para incidir en los factores de riesgo.

Descriptores: Abandono escolar, desigualdad social, educación básica, pobreza, rezago educativo, vulnerabilidad social.

\begin{abstract}
Six Objectives of development of the Millennium focused on childhood were stablished on 2000 with the aid of the 189 countries that form the United Nations, due to the situation presented by children from all around the world. One of the objectives strives to assure that by 2015 all children will complete their primary education. A series of individual and structural factors keep children from staying in school. According to several studies, external factors, such as poverty and gender end up being the key reasons that keep children away from school. This paper has
\end{abstract}

Forma sugerida de citar: Mendoza Cárdenas, Elizabeth \& Zúñiga Coronado, María (2017). Factores intra y extra escolares asociados al rezago educativo en comunidades vulnerables. Alteridad, 12(1), pp. 79-91. 
the objective of showing the result of an exploratory study realized from a mixed focus over the perception that directives, professors, and citizens from Polígono San Bernabé (Monterrey), regarding the factors that promote educational lay back within basic education.

\section{El rezago educativo en México}

Entendemos el rezago educativo como el nivel escolar, de un individuo o un grupo, inferior al nivel académico establecido como mínimo o suficiente. Según Suárez Zozaya (2001), es una condición de desigualdad y falta de justicia en términos de distribución de servicios y oportunidades educativas.

El rezago educativo es uno de los principales problemas que aqueja a México. A nivel nacional, en 2010, el porcentaje de población de 15 años y más que era analfabeta o no terminó la primaria o secundaria fue de $40.7 \%$. El porcentaje de población no terminó la primaria fue $12.9 \%$, lo que equivale a 10082386 personas. En Nuevo León se registra un $28.8 \%$ de rezago educativo, lo que equivale a 958035 individuos que son analfabetas o no terminaron los estudios de primaria o secundaria. Las personas que no terminaron la primaria ascienden a $282141(8.5 \%)$ (INEGI, 2010).

Los factores asociados al rezago escolar son múltiples, por lo que suelen ser estudiados desde dos enfoques. Un enfoque centra la atención en las variables intra escolares y el otro en las variables extra escolares (Espinoza, Castillo, González y Loyola, 2012). Entre los factores internos a las escuelas que intervienen en los resultados académicos están la asignación y administración de los recursos, la capacitación y las condiciones de trabajo de los docentes, los salarios, los planes de estudio, el modelo de docencia, la percepción y creencias de los profesores sobre los alumnos. El enfoque extraescolar señala que las principales casusas del rezago escolar son la situación socioeconómica, la cultura y el contexto familiar de los y las estudiantes. La pobreza, el desempleo, la
The main strategies used by institutions to avoid this issue will also be presented.

Keywords: Drop-out, social inequality, basic education, poverty, educational backwardness, social vulnerability.

baja escolaridad de los padres, la marginación, el embarazo a temprana edad, el consumo de drogas, la desintegración familiar, así como las bajas expectativas que las familias tienen de la educación son identificados como factores del contexto familiar que pueden desencadenar el rezago educativo (Muñoz Izquierdo, 2009).

A pesar de que los factores asociados a los estudiantes, a la familia y a la escuela han sido identificados en una buena cantidad de estudios como detonantes del rezago escolar, el Programa Sectorial de Educación 2013-2018, atendiendo a la recomendación realizada por la UNESCO, en el 2013, le da prioridad a la construcción y rehabilitación de escuelas a fin de que sean más accesibles y seguras. Con el fin de evidenciar la importancia que tienen las variables culturales, familiares y económicas en el rendimiento escolar se presentan a continuación los resultados de un estudio cualitativo realizado en directivos de escuelas que atienen alumnos de bajo nivel socioeconómico, así como de habitantes de la zona.

\section{Esbozo metodológico}

Se trata de una investigación mixta realizada con la participación de habitantes, docentes y directivos de escuelas primarias y secundarias ubicadas en el polígono San Bernabé del Área Metropolitana de Monterrey caracterizado como pobre. Para el estudio se utilizó la estrategia de procedimientos secuenciales del método de investigación mixta. Lo que significa que el proyecto es primordialmente cualitativo y el análisis cuantitativo se fusionó para proveer introspección en diferentes niveles o unidades de análisis a fin de alcanzar una profunda comprensión del problema. 


\section{Metodología cualitativa}

Se estableció un diálogo con los profesores y representantes de las instituciones educativas por medio de la entrevista a profundidad, así como a adultos que residen en comunidades del polígono. El diálogo estaba dirigido a comprender las perspectivas de cada uno con respecto a los factores que afectan el rendimiento escolar de los estudiantes de nivel básico, así como las propuestas para atenderlo.

El primer contacto con el área que abarca el polígono se realizó a través de una visita exploratoria, lo que permitió identificar las organizaciones sociales y las instituciones ubicadas en las colonias, entre ellas a las educativas. Asimismo, el abordaje con algunos habitantes facilitó la identificación y el contacto con otros pobladores; la bola de nieve fue la estrategia utilizada para este fin.

\section{Perfil de los sujetos entrevistados}

Se estableció diálogo con once personas de distintas colonias ubicadas en ocho agebs del polígono San Bernabé del municipio de Monterrey. Seis de los entrevistados tienen cargos en instituciones educativas de nivel primaria, cuatro de ellas ocupan puestos directivos, una se desempeña como docente y otra como asistente. Además, se conversó con un párroco y los cuatro restantes, son pobladores. En cuanto al sexo, tres son hombres y nueve mujeres. Todas las personas son adultas.

\section{Metodología cuantitativa}

Se utilizó el diseño de investigación transeccional o transversal descriptivo y para seleccionar las viviendas del polígono San Bernabé, se utilizó el método de muestreo probabilístico denominado "aleatorio simple". Una vez seleccionadas las viviendas se acudió a los domicilios elegidos y se aplicó un cuestionario a algún habitante que cubriera el requisito de ser mayor de edad. La muestra de los agebs, objeto del presente estudio, consta de 559 domicilios y se capturó información de 2290 personas residentes de las casas seleccionadas. La muestra permite hacer estimaciones con una confianza del $95 \%$.

\section{Resultados}

\section{El contexto}

El polígono San Bernabé se ubica en la parte NordPoniente de la Ciudad de Monterrey. Colinda con el municipio de Escobedo y con el Cerro del Topo Chico. De acuerdo a su morfología comprende dos zonas. La zona de San Bernabé que se caracteriza por ser terreno plano y con equipamiento urbano y La Croc, zona ubicada en lomas, con carencia o deterioro de infraestructura urbana.

San Bernabé/ la Croc, surge como asentamiento ilegal urbano a finales de la década de los sesenta y principios de los setenta. Las viviendas eran precarias, se carecía de todo tipo de equipamiento urbano, como servicios básicos al interior de la vivienda y servicios públicos en la colonia, por lo que la obscuridad y lejanía de los predios promovieron que desde los inicios fueran víctimas de asaltos y robos en las viviendas. Actualmente, el polígono se compone de 28 agebs, que comprenden 32 colonias. Se registran avances significativos de desarrollo urbano en la mayoría de la zona. Casi todas las colonias cuentan con servicios básicos, con escuelas de nivel básico, un CONALEP, un Centro de Salud, plazas públicas, canchas deportivas y un macrocentro. La calidad de las viviendas, también han sufrido transformaciones importantes, pues la mayoría están construidas de materiales sólidos, como el concreto, además, de que se ostenta con el título de propiedad. No obstante, los asentamientos ubicados en la zona alta de la Croc son los más marginados por estar situados en territorio federal. Las viviendas se caracterizan por estar construidas en paredes de madera o block apilados u otro material de desperdicio y con techo de lámina galvanizada, no cuentan con la instalación de servicios básicos, por lo que a través de conexiones irregulares tienen acceso a la electricidad y al agua, además de que prácticamente no se cuenta con vías de acceso. 
La carencia o mal funcionamiento de los servicios básicos, la inseguridad, el desempleo, los bajos ingresos, la desintegración familiar, el rezago educativo son las situaciones problema que actualmente enfrentan los habitantes de las comunidades de San Bernabé/La Croc y las principales manifestaciones de esta son: (Ver Figura 1).

Figura 1. Situaciones problema en las comunidades de San Bernabé/La Croc

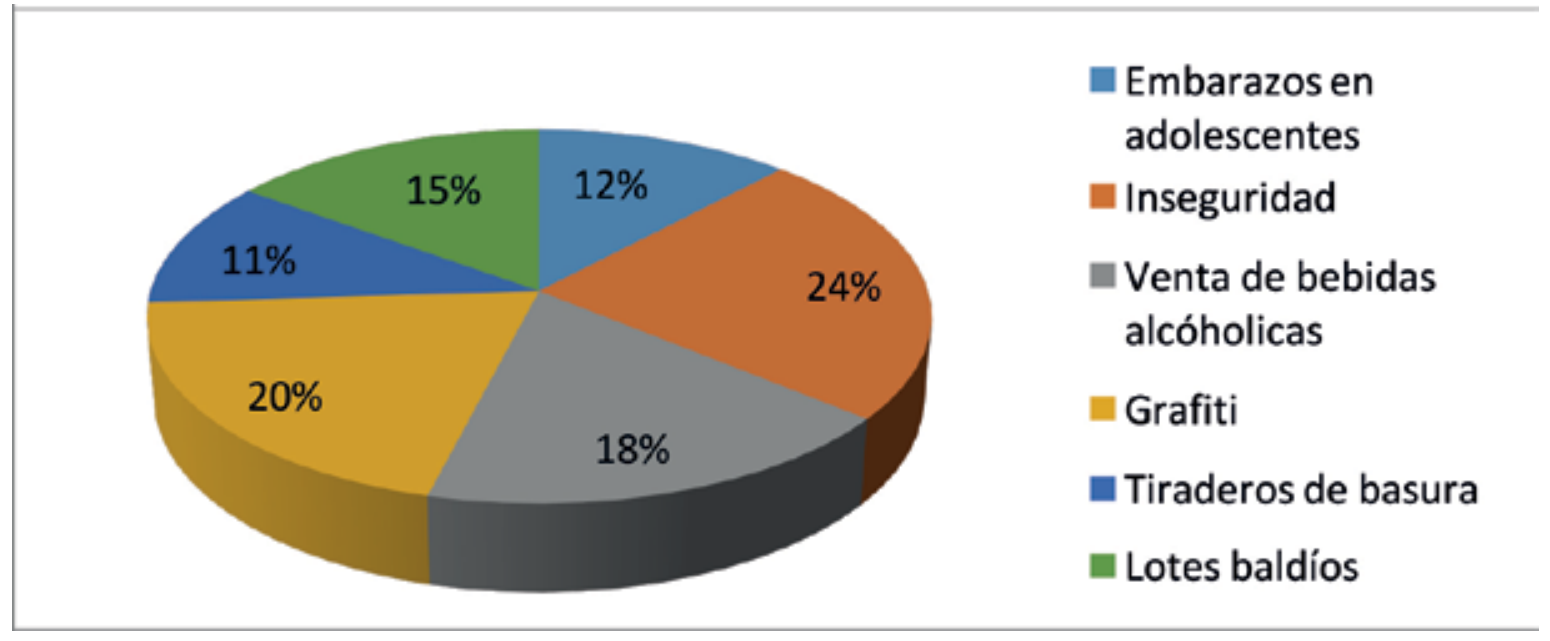

Fuente: Elaboración propia, Ios cálculos presentados se obtuvieron utilizando la información del Cuestionario Línea Base realizado a los hogares, UANL-SEDESOL 2014.

El rezago educativo de estudiantes de la escuela primaria se identifica en nueve agebs de San Bernabé, el 3 (La Croc), 4 y 23 (Ampliación Laderas del Topo Chico), 6 (Gloria Mendiola y
El Porvenir), 12 (Conquistadores/ La Croc), 15 (San Bernabé XIV), 20 (La Croc), 21 (Ampliación Municipal y La Reforma) y 25 (San Bernabé XII). (Ver Figura 2).

Figura 2. Mapa del Polígono San Bernabé/ La Croc

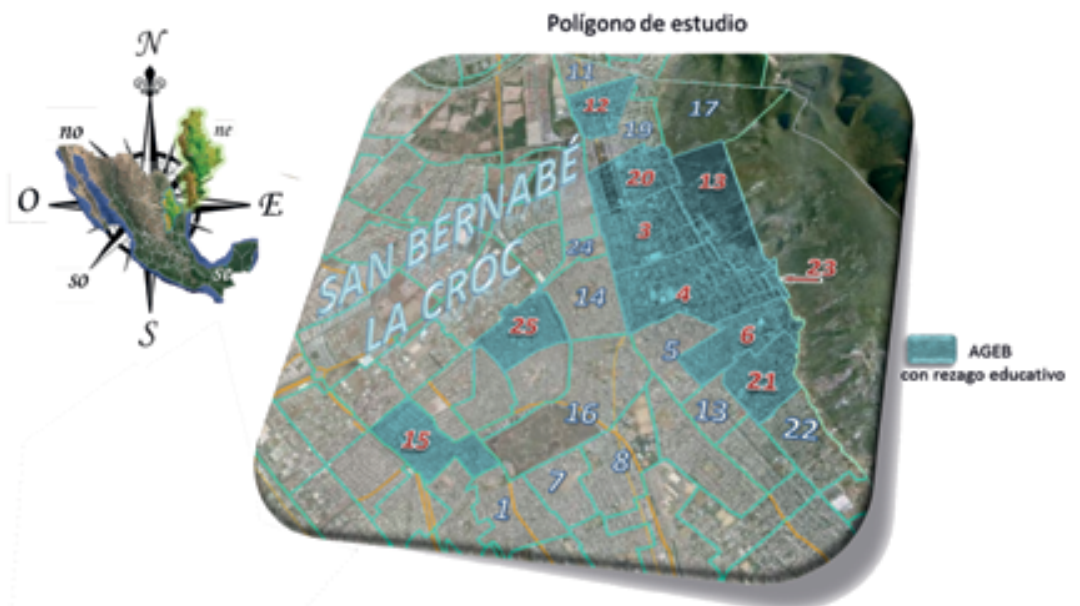


La zona de la Croc, es donde se identifica mayor rezago, en comparación con la zona de San Bernabé. La mayoría de los habitantes de estos agebs cuentan con un nivel educativo bajo, y desarrollan trabajos informales. El grueso de la mano de obra masculina se desempeña como albañiles, carpinteros, soldadores o mecánicos. El comercio informal es el segundo sector donde obtienen ingresos para la supervivencia (Ver Figura 3). En el caso de las mujeres, en general, se desempeñan también en el mercado informal, primordialmente como empleadas domésticas en la zona Cumbres. Debido a las características del empleo, los habitantes perciben salarios bajos y carecen de acceso a servicios de salud y prestaciones sociales (Ver Figura 4).

Figura 3. Ingreso mensual familiar en las comunidades de San Bernabé/La Croc

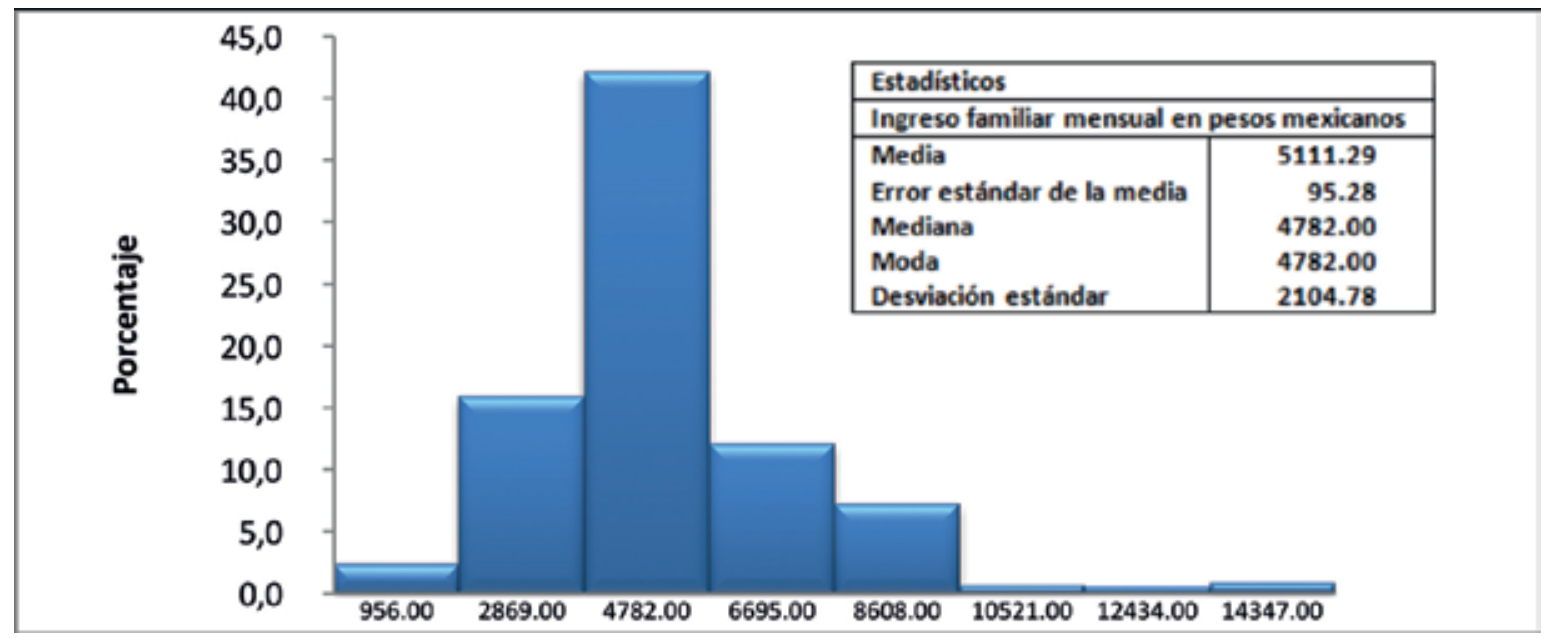

Fuente: Elaboración propia, los cálculos presentados se obtuvieron utilizando la información del Cuestionario Línea Base realizado a los hogares, UANL-SEDESOL 2014.

Las casas son habitadas por cinco per- a finales de 2014, fue de $\$ 5,111.3 \pm \$ 186.75$ sonas en promedio $(\bar{X}=5.13, \mathrm{DE}=\$ 2.205)$ y $(\bar{X}=\$ 5111.3, \mathrm{DE}=\$ 2,104.8)$.

el ingreso familiar estimado en la población,

Figura 4. Afiliación a instituciones de salud de los pobladores en las comunidades de San Bernabé/La Croc

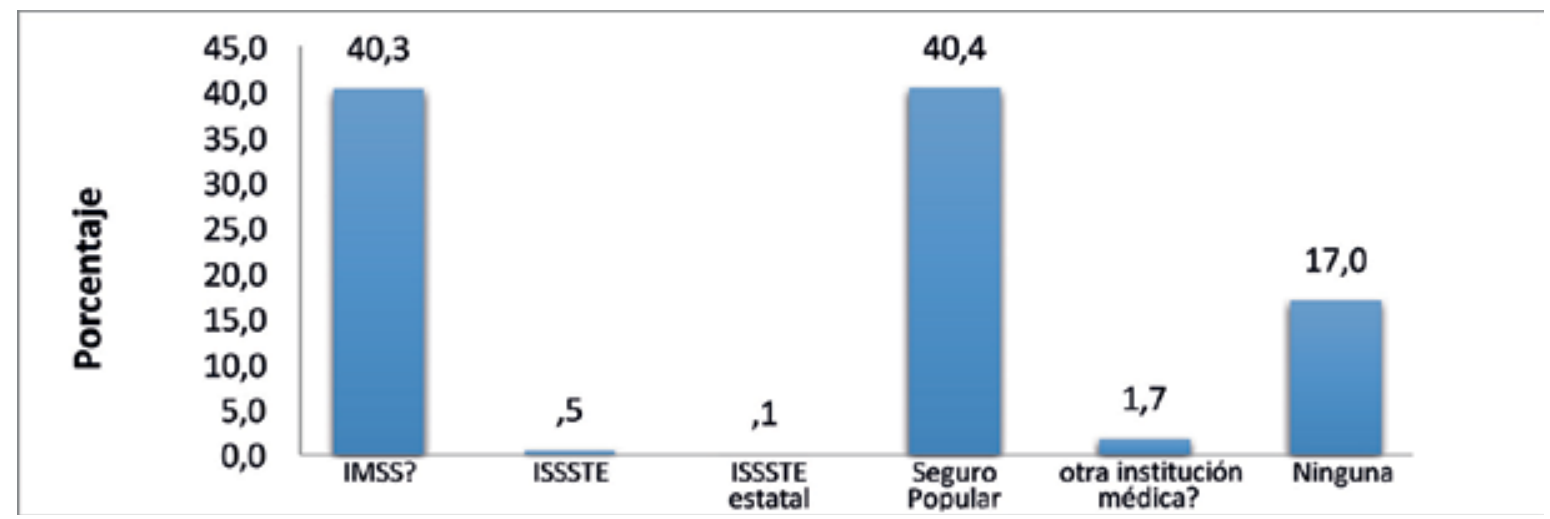

Fuente: Elaboración propia, los cálculos presentados se obtuvieron utilizando la información del Cuestionario Línea Base realizado a los hogares, UANL-SEDESOL 2014. 
El común denominador de estas colonias es la presencia de inseguridad, violencia familiar, desintegración familiar, pandillerismo, drogadicción y desempleo.

\section{Factores asociados al rezago educativo de estudiantes que residen en comunidades vulnerables del municipio de Monterrey}

Múltiples factores intra escolares como extra escolares son asociados por los entrevistados al bajo rendimiento escolar o al rezago educativo de los y las estudiantes de primaria que viven en el Polígono San Bernabé/La CROC, del municipio de Monterrey. No obstante, los factores extra escolares, sobre todo los relacionados al contexto familiar son los que predominan en los discursos de las y los entrevistados. En primer instancia se describen los factores extra aula y posteriormente los factores internos, que desde la percepción de los participantes en el estudio inciden en el rendimiento escolar.

\section{Ámbito extra escolar}

Contexto familiar. En el ámbito familiar, la falta de interés de los padres, el trabajo remunerado del padre y la madre, la desintegración familiar, la violencia doméstica, la pobreza, las adicciones, y la escolaridad de los padres son las principales situaciones identificadas como causantes del rezago escolar de estudiantes de primaria.

Desinterés de los padres. Los padres son los principales actores identificados por los directivos entrevistados de distintas escuelas, como los responsables del bajo rendimiento escolar de los estudiantes.

Este ... el maestro está haciendo su parte como es debido el alumno aquí dentro de la escuela el maestro pues lo motiva a que participe pero el padre de familia que es la otra tercera parte no cumple con lo que le corresponde y por eso la escuela no anda bien académicamente se pudiera decir (Directivo/F/ 4)
La falta de interés y/o apatía de los padres en el proceso educativo se ve reflejado en la inasistencia de los hijos a la escuela y en el incumplimiento de las tareas.

...el padre y los padres que están libres algunos si ayudan pero la mayoría no y cuando citamos, citamos, hemos citado aquí a los papás que te... de alumnos que tiene problema de rezago, aquí nos dejan los niños solos, no vienen, no se presentan, y hay gente como les digo, hacen de cuenta que la escuela es una guardería o un internado, aquí traen el niño en agosto y no vienen por el hasta junio por la calificación, por julio por la calificación, pos nunca los conocemos, tiene mucho problema de ausentismo, de deserción interna que van y vienen, o sea se va, que van a San Luis o que van a otro estado y luego que regresaron... Es desinterés y apatía que tienen, en primer lugar , a que voy si siempre me van a regañar porque mi hijo no trae tareas, porque o sea ya a veces lo recibimos, nosotros no tenemos culpa si le decimos al papá, siempre con negativo, jamás citamos al bueno... (Directivo /M/12).

...el problema que tenemos es la inasistencia, en la inasistencia se batalla mucho, hay mucha irresponsabilidad de los papás, que siempre estamos insistiendo en que nos los envíen diario, pero siempre hay niños que faltan. Es el problema más grande y eso ocasiona el rezago escolar, que los niños se vayan rezagando, este, que viene siendo en su aprendizaje... (Directivo /M/20).

Y en la inasistencia es rotundamente la irresponsabilidad por parte de los padres de familia,..., todos llegando tarde, todos llegando raspando, todos de que, "es que me quede dormida" infinidad de pretextos, así rotundamente, irresponsabilidad de los padres de familia, eso es, en la inasistencia. (Directivo/F/25).

La familia es identificada, por los responsables de las escuelas, como agente importante de socialización en la transmisión de normas y valores para la vida, la escuela y el trabajo, no obs- 
tante, los padres no se desempeñan como agentes transmisores de los valores que son fundamentales en la educación.

Los valores que es, que, los maestros fomen$\tan$, le digo los valores ya los traen de su casa, los maestros nomas los fomentemos, no los hacemos, algunos ya los traen, los valores pues la asistencia del alumno al venir a una escuela...35 años de servicio toda la vida hemos batallado con la puntualidad, pero digo es una cultura mexicana el ser impuntual sí, por eso (Directivo /M/12).

La falta de participación de los padres en el proceso educativo es desalentadora de acuerdo a la percepción de los entrevistados, por la creencia que tienen los padres de que los maestros son los responsables de educar y formar a los estudiantes. El bajo nivel educativo de los padres (Ver Tabla 1), es otro factor que contribuye al fracaso escolar de los hijos.

..., porque quieren que el maestro haga $y$ tengan la varita mágica para que les eduque, aparte de formarlos, que eduquen a sus hijos, error (Directivo/F/25).

...pero como las personas, muchas de aquí de, de esta colonia, desgraciadamente no, no estudiaron más que hasta la secundaria o, o ni la secundaria porque la mamá de estos niños no sabe ni leer, tiene que poner la huella cuando yo le mando a, a que firme un documento ella tiene que poner la huella porque no sabe ni leer (Dependiente/F/3).

Tabla 1.Nivel escolar de personas con 15 o más años de edad que no estudian

\begin{tabular}{|l|l|l|}
\hline \multirow{2}{*}{ Escolaridad } & \multicolumn{2}{c|}{ Sexo } \\
\cline { 2 - 4 } Ninguno & \multicolumn{1}{c|}{ Mujer } \\
\hline Primaria & 41 & 50 \\
\hline Secundaria & 201 & 272 \\
\hline Preparatoria & 339 & 296 \\
\hline Normal & 98 & 88 \\
\hline Carrera técnica o comercial & 1 & 2 \\
\hline Profesional & 21 & 37 \\
\hline Total & 23 & 20 \\
\hline
\end{tabular}

Fuente: Elaboración propia, los cálculos presentados se obtuvieron utilizando la información del Cuestionario Línea Base realizado a los hogares, UANL-SEDESOL 2014.

Trabajo remunerado del padre y la madre. El trabajo de ambos padres, particularmente la incorporación de la madre al mercado laboral, es visto como un obstáculo importante del fracaso escolar de los alumnos. Las largas jornadas de trabajo, aunadas al tiempo invertido en el trasla- do, impiden contar con tiempo para apoyar y dar seguimiento a la trayectoria escolar de los hijos.

... la mamá está sola, se va a trabajar, el papá está, puede estar en el penal, porque nos ha tocado casos, a mí me ha tocado muchas situa- 
ciones de esas entonces pues ahí si vemos que le niño está desprotegido... (Directivo/M/12)

Se da por la falta de apoyo por parte del padre de familia, son papás poco responsables en cuanto al apoyo para sus hijos, se dedican a trabajar o hacer otras cosas, y no ponerle atención al hijo, le dan importancia a otras cosas, menos al hijo,... (Directivo/F/25).

las mamás trabaja, pero, trabaja en empresas que les pagan, bien poquito y tienen que trabajar 8 horas y más, con, con, con el traslado del, del camión y todo eso, las señoras están fuera de su casa 12 horas, si, entre ida y vuelta, entonces por eso es que también los niños luego bajan de calificación porque las mamás no, no les ayudan a hacer tarea y, y no se dan cuenta de, de lo que está pasando en...a veces vienen y no saben el nombre del maestro de su hijo (Dependiente /F/3).

...es que a muchas personas como padre de familia, por trabajar, no les ponen atención a sus hijos no saben con quien se juntan ni nada... (Habitante/F/18).

Violencia doméstica. La violencia familiar es identificada como situación que se presenta con frecuencia en las familias.

Pues aquí anda mucho los pleitos en los matrimonios, los golpes, pues si, este casi por lo regular no hay familia que la mujer lo engañó, que el señor golpea a los niños o sea es uno de los problemas yo creo que más se han visto aquí en la colonia (Habitante/F/25).

El maltrato físico y/o psicológico, por parte de algún miembro de la familia, como el padre o el padrastro, provoca consecuencias importantes en la salud psicofísica de los estudiantes.

...se suscitó una problemática con una maestra que tenía al niño que no se podía levantar, y es que no se quiere levantar está llore y llore, y que no puede apoyar los pies, bueno pos que tiene, ve... vengo, le digo al conserje me lo train para acá y yo vi las piernas y estaban todas moretoniadas y lo habían agredido el padrastro con un palo de escoba y a la hermanita que estaba en segundo me la traje también y le empecé a preguntar y dijo es que mi papá no nos... es tu papá el que les pega? (Docente/F/12).

...falta mucho respeto entre el padre de familia y el niño porque parece, digamos el caso, que un padre de familia le llama la atención al niño con palabras muy fuertes, a veces con maltratos (Directivo/M/20).

Sí, si hay maltrato, si hay maltrato porque, eh, quieren que los niños hagan todo, sin ellos poner algo de su parte, y cuando son desobedientes los niños, pues viene el maltrato, de que, si yo soy el papá, si yo soy la mamá, el que obedezcas, y estoy de acuerdo, pero mientras no tengan valores en su casa y no les fundamentan, pues el resultado ahí está, les faltan al respeto, no les gusta y es donde hay maltrato, ...(Directivo/F/25).

Desintegración familiar. El cambio de domicilio o el bloqueo psicológico que sufren los estudiantes cuando los padres se separan o divorcian obstaculiza el avance académicos.

... el famoso, el famosos caso que se fue mi papá, verda, entonces, nos vamos a ir con mi abuelita que vive en otro estado o que se viene el otro esposo para la señora y ya tiene a su señor esposo y luego que viene el papá verdadero y se lleva a los niños, no, problemas, problemas fuertes entre los muchachos, que vemos veda, aquí es muy difícil en cuestión de los problemas psicológico, es muy difícil, si nosotros tenemos un niño o varios niños con problemas obviamente no va a avanzar, va a estar ahí bloqueados entonces yo por eso yo veía oda esa problemática (Directivo/M/12).

...la desintegración familiar de los padres de familia y hay otro problema aquí de que pues hay familias, mínimo verdad pero hay familias donde se consumen droga, entonces es otra cosa que los niños traen, lo ven y 
ellos nos lo platican, pero en minoría, así que principalmente es la desintegración familiar (Directivo/M/20).

En otros casos, el rompimiento del vínculo marital provoca el abandono de los hijos por parte de la madre. Situación que repercute en la estabilidad emocional del niño y en el desempeño académico. Siendo las abuelas las que toman la responsabilidad de la crianza y educación de los nietos.

Muchísimos, muchos casos. No, no lo tengo, pero sí hay, hay madres solteras, divorcios, abuelitas encargadas de los nietos, porque la mamá los dejó, la mamá no se hizo cargo de ellos, se juntó con otra pareja y ya no se los llevó (Directivo /F/25).

Pobreza. El rezago educativo o deserción escolar se desencadena también por razones económicas. Los hijos son utilizados por los padres como instrumento para obtener ingresos para completar el gasto familiar, por lo que en vez de asistir a la escuela, deambulan por las calles o en camiones de transporte público pidiendo dinero o vendiendo algún artículo con el fin de obtener ingresos económicos para completar el gasto familiar.

...alguien que a esos niños los rescate porque cuando esos niños no vienen a la escuela es porque andan pidiendo limosna arriba de un camión, me consta, los han visto, si, venden paletitas venden dulcitos y le ayudan a su papá a, andar vendiendo estampitas de no sé qué para que, para que ellos tengan, los papás, tengan comida, cuando los papás son los que deben de trabajar no ellos y así es,... (Dependiente /F/3).

Petrita (nombre ficticio) que fue la que salió de la secundaria no ha sido atendida y la señora no la está llevando a la secundaria, anda en las calles pidiendo limosna, vendiendo cosas en los camiones, y la otra vez la vi aquí en la cuadra con otra persona de la misma estatura que ella ósea, otro enanito, pero no era su papá, era un jovencito, la niña ya tiene 13 años, verdad, la están descuidando pero ahí no dicen nada en la televisión, no dicen que los papás están fallando como papás (Dependiente /F/3).

De la muestra analizada encontramos 377 jóvenes en el rango de nueve a diecinueve años de edad, de ellos, actualmente 103 no estudian. A partir de este dato podemos estimar que el $27.3 \%$ $\pm 4.5 \%$ de los habitantes en ese rango de edad presentan rezago escolar y expresan como principales motivos para abandonar sus estudios: la falta de dinero, no les gusta estudiar y necesidad de trabajar (Ver Figura 5).

El hambre es también un impedimento en el proceso de aprendizaje de los estudiantes. El hambre y la mala nutrición perturban el progreso escolar porque se reduce drásticamente la capacidad de atención y de concentración.

...aquí con los niños, en mala conducta, en agresión de un niño para otro y en no avance en el rezago por que el niño no se puede concentrar porque tiene hambre, porque está pensando que su papá golpeo a su mamá, está pensando que su mamá llegó tomada o borracha o está pensando en que su papá se durmió... (Dependiente /F/3).

Adicciones. Las adicciones al alcohol y otro tipo de drogas de los padres provocan la falta de apoyo en distintos ámbito, entre ellos el educativo.

Los problemas en los estudiantes son muy marcados, he, hay la tomadera, drogadicción y que los padres no están en casa con ellos, eso es problemático, muy grave aquí en la comunidad. (Directivo/F/25).

La falta de identidad legal, excluye a los niños y niñas de la escuela, puesto que al no contar con el acta de nacimiento no se les permite ser inscritos.

... mmm, siempre o sea bien raros los rostros que sean que las parejas se peleen así, o de los niños o sea hay muchos niños que no están en la escuela o registrados aún; y bueno pss eso también, ss es que necesitan checar así veda familia por familia y si van a encontrar muchas 
que si tú les pides el acta de nacimiento a lo mejor ni la tienen... (Habitante/F/15).

\section{El ámbito intra escolar}

En el ámbito formal, se observa la falta de apoyo de los directivos de las escuelas y de la Secretaría de Educación para que los y las profesoras puedan intervenir en ciertos factores asociados al rezago, como el maltrato infantil y la falta apoyos materiales (libros de texto).

La respuesta de los directivos de las escuelas ante los casos de maltrato es la indiferencia o complicidad, rehusándose a intervenir o tratando de impedir que los profesores intervengan, debido a que tienen que acatar la instrucción de la Secretaría de Educación de no involucrarse en estos casos.

...y claro que me metí en un problemón con la directora porque no quería, dije pero yo tenía que hacer eso, porque no, porque, maestra es que mire van a venir los medios y que, maestra y que quiere que yo haga aquí no van a venir con nosotros porque no fue agredido aquí, pero si yo no lo hubiera hecho, hubieran dicho que maestra tan inconsciente como lo ve golpeado y no actuó, entonces que podía haber hecho maestra? (Docente/F/12).

Y esto no es de,... esto es de la misma Secretaría, de que son como dependencia inconsciente, incongruente, porque lo primero que nos indica, tú no te metas (Directivo/M/12).

La no distribución de los libros de texto por parte de la Secretaría de Educación favorece el rezago educativo de los niños del polígono.

... la falta de apoyo total del padre de familia, falta de apoyos materiales de la Secretaria de Educación como son los libros de texto, que, no sé, por ser, por turno vespertino... (Directivo/M/12)
La impuntualidad e inasistencia de los profesores, así como la falta de planeación y de seguimiento de la trayectoria escolar de los estudiantes promueven también el rezago escolar.

...y he quitado muchos vicios que tenían los maestros por ejemplo que no llevaban una planeación por ejemplo que no registraban los trabajos de los niños en las libretas yo les pedía la libreta cuando yo le...-mándeme la libreta de donde tiene la asistencia donde tienen la calificación- y los maestros-: ¿cuál libreta maestra?-, la libreta que deben de llevar, el registro- me la mandaban no se ya teníamos un mes en la escuela los maestros tenían una o dos calificaciones y yo -que pasa con que califican ustedes tienen que registrar - y empecé y empecé a pedirles y a pedirles y ahorita ya se acostumbraron que tienen que mandarme la planeación ,la libreta de asistencia la libretas de calificaciones y que tienen que promediar con los trabajos diarios si , el examen, entonces hemos ido avanzando y este... falta mucho por hacer todavía, pero, pero ya los maestros, ya no faltan, ya llegan temprano, trabajan en equipo, tenemos proyectos y los llevamos a cabo y tenemos evidencias (Directivo/F/ 4).

[...] Los niños descuidados, muchos no son atendidos en las escuelas, muchos maestros que vienen a clases acá, no quieren venir para acá, entonces vienen a regañadientes, porque requieren una plaza, entonces también repercute en el trato con los niños, entonces nosotros por ejemplo, comenzamos queriendo tener una relación con los maestros, con las escuelas, diciéndoles a ver, en el catecismo nosotros percibimos que estos niños no aprenden, queremos que nos digan cómo están allá en la escuela, a la mejor trae un problema familiar y necesitamos detectar cual es el problema, para darle solución de fondo, juntos, no quisieron, no quisieron, porque mucho problema se genera en la escuela (Párroco/M/21). 


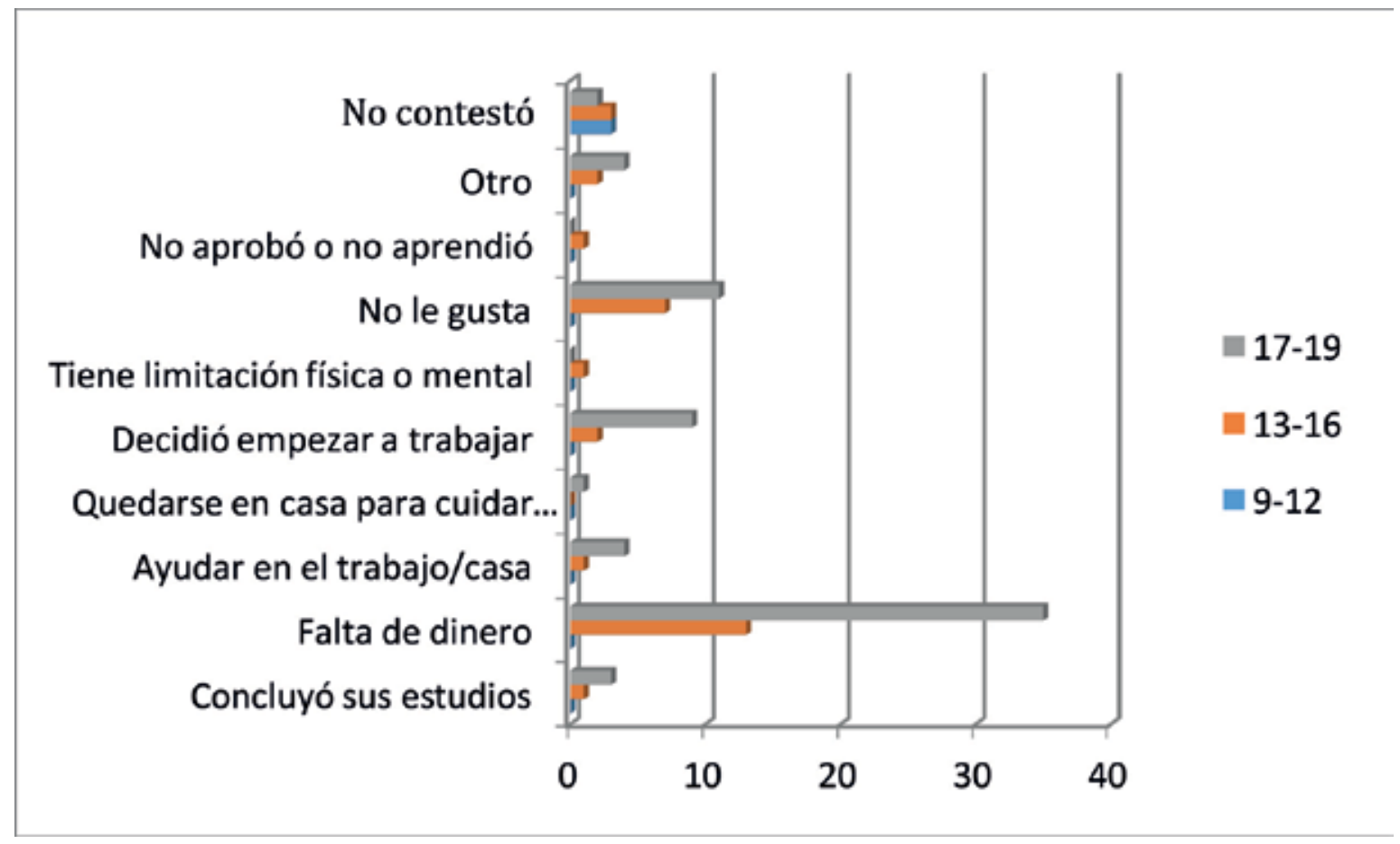

Fuente: Elaboración propia en base a los datos de la Línea Base

\section{Estrategias de afrontamiento}

Entre las principales estrategias que se realizan en las escuelas para incidir en los factores familiares, está la realización de talleres escolares y los talleres de valores dirigidos a padres de familia y a estudiantes, así como los proyectos de apoyo académico.

El objetivo de los talleres escolares es fomentar la participación de los padres en el ámbito académico, promover la comunicación entre padres e hijos y entre padres, profesores y directivos.

Ahorita lo estamos viendo frecuentemente, por ejemplo tenemos fechas marcadas, la semana pasada convivieron 4 grupos, la semana empezó uno ahorita y ósea están las actividades marcadas para cada mes, en las juntas de consejo técnico, marcamos las actividades marcamos todos los grupos y estamos, o sea se están calendarizando para que todos los papás, si tienen por ejemplo, que si tienen hijos en tercero y en quinto, bueno que en este día venga con los de tercero y el día que le toca el quinto, venga con los de quinto. Para que convivan y realicen actividades con sus hijos y cumplen con uno y cumplen con el otro, que los agenda todas esas actividades y con los papás se les envía la invitación (Directivo/F/25).

Del año pasado para acá, yo, se ve una falta grande de valores, me di a la tarea como les digo de estar abierta para los padres de familia en la comunidad, comunicación, y que ellos entiendan, que la responsabilidad dentro de casa fomentando los valores (Directivo/F/25).

Los proyectos de lectura, de escritura y de matemáticas están encaminados a brindar capacitación y asesoría en las áreas donde se presenta mayor rezago. 
...planteamos proyectos para sacar a los niños del rezago educativo como por ejemplo proyectos de lecto-escritura de matemáticas, emm de escritura y de valores, por ejemplo, también eh hacemos los que están en nuestras manos aquí en la escuela... (Directivo/F/ 4).

La ruta de mejora es también implementada para que los estudiantes no se rezagen. [...] bajo rendimiento, bajo rendimiento, por eso estamos ahora implementando muchas estrategias, lo que es la ruta de mejora, buscándoles estrategias adecuadas, para que no se nos queden niños rezagados o en peligro de reprobación, también estamos enfocados mucho en combatir la violencia entre ellos mismos se esté... (Asistente escuela/F/ 6).

\section{Conclusiones}

La etiología del rezago escolar de los y las estudiantes que viven en el Polígono San Bernabé/La Croc se debe tanto a factores extraescolares como escolares. Los factores que no dependen de los esfuerzos de los alumnos, pero que interfieren en el aprovechamiento escolar son principalmente la pobreza y la falta de apoyo familiar.

El factor económico ha sido atendido por el gobierno a través de subsidios en efectivo que las familias reciben a través del programa "Oportunidades", gracias a lo cual se ha logrado la permanencia de algunos niños y niñas en la escuela. Sin embargo, el uso inadecuado que algunos padres de familia hacen de dicho recurso gubernamental, así como las características del empleo y la percepción de ingresos precarios continúan incidiendo en el rezago escolar en estas zonas.

La variable familiar, interviene también en forma significativa en el rezago escolar. La desintegración de la familia, la violencia doméstica y la incursión en el mercado laboral, tanto del padre como de la madre, inciden de manera directa en el estado emocional y por ende en la salud mental de los hijos, afectando su rendimiento escolar.

Los factores internos a las escuelas intervienen también en forma significativa en el rezago escolar, principalmente la indiferencia de parte de las autoridades de las escuelas así como de la Secretaría de Educación ante los efectos que la situación familiar está teniendo en el aprovechamiento escolar. La poca presencia de otros profesionistas, trabajador@s sociales, psicólogos, etc., para atender los aspectos relacionados a la salud mental de los alumnos y alumnas, así como los relacionados al contexto familiar (violencia, desintegración, etc.) es una muestra del olvido o indiferencia de esta problemática.

Para combatir los factores que impiden que los estudiantes puedan concluir el ciclo escolar es necesario implementar diversos programas sustentados en un diagnóstico tanto cualitativo como cuantitativo de cada colonia y familia. Los programas serán más eficaces y eficientes se están basados en las características, intereses y necesidades de los actores involucrados, así como en las de su ambiente. El diálogo entre los distintos actores involucrados debe prevalecer sobre las formas verticales de acercamiento para el trabajo conjunto. Las acciones deben apuntar hacia la re significación que tienen los padres y los y las estudiantes de la importancia de la educación en la calidad de vida, más que en la reeducación de los padres, así como a establecer alternativas para que los niños que no reciban apoyo en su casa para las tareas escolares puedan recibirlo de otros actores de la comunidad, como los estudiantes de preparatoria y universidades, a través de la formación de clubes de tareas.

\section{Referencias bibliográficas}

Espinoza, O., Castillo, D., González, L. E., \& Loyola, J. (enero-marzo de 2012). Factores familiares asociados a la deserción escolar en Chile (Ve). Revista de Ciencias Sociales, XVIII(1), 136-150.

INEGI (2010). Censo de población y vivienda 2010. México. INEGI.

Muñoz Izquierdo, C. (2009). Construcción del conocimiento sobre la etiología del rezago educativo y sus implicaciones para la orientación de las políticas públicas: La experiencia de 
México. REICE. Revista Iberoamericana sobre Calidad, Eficacia y Cambio en Educación, 7(4), 28-45.

ONU México (2000). Objetivos de Desarrollo del Milenio. ONU. http://www.onu.org.mx/ objetivos_de_desarrollo_del_milenio.html. Consultado el 15 abril del 2014.

Secretaría de Educación Pública (2013). Programa Sectorial de Educación 2013-2018. México: SEP.
Suárez Zozaya, M. H. (2001). Rezago educativo y desigualdad social en el estado de Morelos: retos de la gestión social. México, D.F.: Universidad Nacional Autónoma de México.

UNESCO (2013). Compendio Mundial de la Educación 2012. En Oportunidades perdidas: El impacto de la repetición y de la salida prematura de la escuela. Quebec: UNESCO/ Instituto de Estadística. 